\title{
A Revision of the Methodology Used for Oral Expositions
}

\author{
Conchi Hernández-Guerra \\ University of Las Palmas de Gran Canaria, Spain
}

\begin{abstract}
Oral expositions in English for foreign students are probably the most difficult activity they can deliver. Lack of practice and fluency, English level and self-awareness in the task make them feel nervous and stacked in many occasions. But, on the other hand, this is a necessary skill in the development of any degree or for future situations they may face in working environments.

Added to this, teachers at high schools do as much as they can taking into account the working conditions: high ratio and few hours. The oral practice is time-consuming and students still do not see the importance of the task and feel more embarrassed than at University.

The aim of this paper is to do some research on the preparation and delivery of an oral exposition. The exercise finishes with a survey offered to the students of the first year in the degree of Modern Languages at the University of Las Palmas de Gran Canaria. We can conclude that only pages on the net were checked in the preparation of the task and hardly the library of the Faculty; in the analysis of the exposition itself, they agree that they could do much better if they had practiced more often. Some proposals are offered in the conclusions.
\end{abstract}

Keywords: Oral skill preparation delivery survey

Subject classification: Teaching classification

Type: survey

Date of Publication: 2018-09-30

DOI: https://doi.org/10.24297/jal.v9i1.7671

ISSN: 2348-3024

Volume: 09 Issue: 01

Journal: Journal of Advances in Linguistics

Website: https://cirworld.com

This work is licensed under a Creative Commons Attribution 4.0 International License.

Website: https://cirworld.com 


\section{Introduction}

Oral expositions have become an indispensable tool to succeed in any degree and for the development of a future job. The ability to speak to an audience is an invaluable asset that will open many doors over time. Speaking properly in your mother tongue reveals many virtues in your personality but the ability to speak up accurately in a foreign language does not just represent proficiency in such language but also reflects ability to communicate your ideas clearly, a deep knowledge of that issue and self-confidence, among other advantages common to any good exposition.

Spanish students have always complained of the lack of fluency in the oral expression in English. Indeed, teachers in lower levels do their best and the preparation of them is already remarkable but the main problem is the high rate of students in every class and the reduced number of hours for English per week. Nevertheless, current students have better advantages than some years ago. For instance, they have at their disposal original versions of the movies, foreign radio stations, youtube tutorials and videos of every topic they like, and so. This is not in itself oral expression but the more you listen to real English the easier it will be to imitate and acquire the accent and fluency.

This is true but in order to improve the oral proficiency it is necessary to practice spoken English. In the years I have been teaching English at the University I have had few students that have decided to speak in English with their classmates on their own. They are the least and it is necessary to be mature enough to have that sense of responsibility. Secondly, and fortunately, Erasmus exchange allows students to live in a foreign environment that even if it is not an English-speaking country, with this language they can manage to survive. On the other hand, not all of the students may or want to enjoy this exchange and they put aside the practice of English as something secondary. They face it just when they have to cope with an exam or the language is required in an interview.

But these students have the advantage of having chosen the degree they want to study. Indeed, there is an extra motivation to learn and find answers. As Thi Thuc Bui said (2013: 1): "Learners with positive attitude towards speaking English will be more involved in speaking activities and may try to make use of more strategies that help them deal with their difficulties in the course of conversation."

All these circumstances mentioned above are typical for students that study a degree not closely related to languages but these characteristics are key when we deal with students that have chosen the study of languages as the priority in their curriculum. They look enthusiastic a priori but the shyness, laziness or the lack of habit make them procrastinate the practice of the oral English. Otherwise, they have an advantage over the rest of the students. They know that the proficiency of the language is the core and main aim of the studies they are developing. The enthusiasm they show is probably much more considerable than in other grades. The teacher must take advantage of this and try to promote the practice of the oral skill in an attractive and efficient way in order to obtain the best results. Another element to consider is anxiety. Students are not used to speaking in English and the fact of speaking to the teacher or to the whole group make the result be lower than could be expected (Utani, 2012: 93). Spielberg defines anxiety as the feeling of uneasiness and apprehension, usually about a situation with uncertain outcomes (see Utani, 94). This final idea is related with the poor preparation of the task. For this reason, the practice of the oral English cannot be considered a single and isolated activity to be graded but a daily activity that will be graded in a specific moment.

This paper reflects the result of a task done with students of the first year of the degree of Modern Languages. The main problem I face with these students is the high pupil-to-teacher ratio. Indeed, two groups of 60 students each is a too high number for keeping debates or other forms of practicing spoken English. Pair work and group work is practiced almost daily but it is impossible to monitor. For this reason, the preparation of an exposition is a good way to evaluate their progress aware that the preparation of the exercise is even more important than the exposition itself. So the steps to be followed during the process is something that the teacher must highlight. 
In this paper I shall explain the different accomplishments followed in class by the students to do an oral presentation. After that, they filled in a questionnaire in which they expressed their strengths and weaknesses in the exposition. In this way, I want to show that the well-known concept of long-life learning must be applied even in class. To put in a nutshell, the activity cannot last one or two sessions but must be prepared during several weeks; secondly, the more information you read the better the exposition will be.

\section{Literature}

Many are the studies that have been carried out in the search of the theoretical best way of improving and practicing the oral skill with students. Nobody questions already the benefits of having a good communication in a foreign language, no matter the studies being done. Indeed, communication, negotiation, and discussion are key elements these students will face in the future. And the English teachers cannot take it for granted. For this, many are the experiments carried out in order to improve the proficiency of the oral skill and the enthusiasm of the students to get the most of their abilities. I have based the revision of the literature on that research based on the different strategies used to improve the oral practice.

I have divided up the literature reviewed in two big blocks: strategies followed before the exposition; that is, the preparation, meetings and practice of it and, on the other hand, the exposition itself of the presentation. Different elements are also considered: body language, tone, slides, content, and so on. It is difficult to stablish a clear line that divides both groups as in some occasions both options are dealt with in the research done, but with the information offered by both we can have a clear vision on how things are worked on.

\section{Preparation of the exposition}

Myers (1995) made a sort of experiment for improving the oral expression and consisted in working hard with pronunciation and the recording of specific structures. In this study she considers the importance of automaticity for the improvement of the oral skill. Automaticity is the repetition of key structures in a natural way. By this, she doesn't mean drills as they are isolated sentences but the repetition of utterances. She did this practice for ITA students. That is, future English trainers. But what is remarkable in this paper is her opinion that oral production could not be based on written production as both are completely different and require different structures. She also provides different authors that support this (Halliday, 1987; Wennerstrom, 1992; and Poirirer, 1993). Actually, she reckons that one is more spontaneous than the other but as Chafe and Danielewicz state: lectures represent "a mixed kind of language, still controlled by the constraints of rapid production, but striving after some of the ... detachment of formal writing" (see Myers, 1995: 236).

Al-wossabi (2016) agrees to some extent with Myers in his study. He offers an interesting list of activities that can be done in class to practice oral English but in the topic we deal with he considers that a prepared talk must not be memorized. On the contrary, some notes can be written on a piece of paper to work as a guide. He highlights the importance of giving students the chance to speak in class and not focus the whole hour on the exposition of the teacher. He also makes an interesting reflection when states that "Students should feel that they are contributing to their own learning and not only satisfying their teachers' demands or final exams' requirements" (2016: 2066).

De Grez (et al.) (2009) made an "attempt to evaluate a multimedia instructional approach that is grounded in social cognitive theory" (114). That is, in his paper he explains that students received instructions from short video clips in which how to perform was shown. But students do no deliver only one presentation but up to three. Every single one was delivered after some instructions and with a feedback. In the final survey they stated that they learnt more from the feedback and secondly from the video clips. Video clips related to what should and should not be done in a presentation and the best presentations delivered. Related to this, Tsai (2010) also explains the experiment done in Taiwan with Business students to enhance oral presentations. It had two phases: the design and structure of the courseware, and integration of courseware into instruction (1246). The first one is a list of instructions and expressions related to the topic to be dealt with. They are provided with some interactive activities about them and terminology, translator, and so on. In the final survey 
several items had to be considered, not just the presentation itself. They are: pronunciation, vocabulary, grammar, sentence patterns, appropriate clothing, body movement, gestures, layout, information per slide, background choice, volume, intonation, pauses, stress. They had to answer which items they felt had improved and needed improvement.

Quite practical and related to the studies above, Wiese (2002) proposes four different sessions to prepare the oral exposition for students of medicine. In the first session, students had to create a historical of a patient from a list of diagnoses. Secondly, students simulate a physical examination of the patient and conclude on the patient's problem taken the diagnoses into consideration. Thirdly, students have to explain the conclusions approached taken the first and second session. In this, they have to explain what is the most probable diagnoses and others that could also be taken into consideration and explain with the data. Finally, students have to adapt "the standard case presentations to the intensive care, outpatient and consultation presentation." (p. 213)

\section{Delivery of the presentation}

According to $\mathrm{Yu}$ (2013), indirect strategies help students to learn a language. He divides them up into metacognitive, affective, and social strategies. And I think this can fit with the preparation and exposition of an oral presentation. The first one has to do with the own cognition of the student: the process of arranging the task and preparing it. For this it is necessary that teacher gives a rubric of the exercise. Whether students know exactly what will be graded will help them to know how to prepare the lesson. In this way they will avoid wasting the time surfing on sources without a goal. Yu also includes in this group the act of self-monitoring; that is, the awareness of the mistakes made while preparing the task. To do this, he proposes to record their own speech and check if it sounds as proper English.

The second one deals with the emotions, how to do to develop a proper presentation, the personal impromptu in the task. This is not a direct strategy but indirect as it deals with emotions. They include techniques to get relaxed and positive; and the third one, or social strategies, covers the group work necessary for the organization of the task: The correction of the mistakes among themselves and the possible observations that others can give you to improve your delivery. As we see, the delivery is not included, that is the final result of the performance, but all the previous work and strategies developed for the well doing.

Chou (2011), also states that cooperative learning strategies and group work enhance a lot the learning and improving of oral skills. He also paraphrases Cohen (1998) by saying that learning strategies and language use strategies become essential to comprehend materials and to give a speech. He divides them into 4 categories (see also

Cohen \& Dörnyei, 2002):

1. Retrieval strategies: strategies used to call up language material from storage, and to memorize or recollect information that has been forgotten.

2. Rehearsal strategies: strategies for practising target language structures, which can be part of language learning or part of language use.

3. Cover strategies: strategies for creating an appearance of language ability, so as not to look unprepared, foolish, or even stupid and

4. Communication strategies: strategies used to convey a message that is meaningful and informative for the listener or reader, such as topic avoidance, message reduction, code switching, and paraphrasing; or leaving a message unfinished if information cannot be bridged. 
In this study the students were asked whether they preferred to do group presentations or oral presentations. Most of them (35 out of 52) agreed in that they preferred individual for several reasons. Among them, the independence to express their opinions, organize the content and choose the topic. Another reason is to avoid the disagreement between the members that consume a lot of time.

Gallagher-Bert (2007) in her study done for the PhD. with German students in Britain realized that students do not like improvisation as they do not feel confident with the mastery of the language being learnt. Indeed, they pose more importance on elements like practice and revision rather than others more spontaneous. Anxiety and the feeling that other students do better than them in an environment where all the students are learning are relevant items to take into consideration. The sense of ridicule and of making mistakes contrast a bit with the idea that "having a go" when speaking is considered.

Grace and Gilsdorf (2004) propose a series of strategies to improve the oral skills in accounting students as they are considered the most reluctant to speak aloud in class. They consider that it is more relevant in this task confidence rather than brilliance. What they propose is to grade the presentation taking into consideration next parts:

1. One-minute self-introduction. Ungraded.

2. Five-minute presentation of accounting exercise. Graded.

3. One-minute response to instructor question. Graded.

4. Five-minute summary of current business news feature. Graded.

These four activities are not done the very same day but during different weeks of the semester. The purpose is to create confidence in the students with activities that have to do with their studies. The first one is not graded as the information that students provide is quite personal and they can decide what to say. It cannot be as simple as my name is... and I am an accounting student but some relevant and unique information about oneself. Next exercises, as we see, are more related to the subject itself.

Indeed, the second is a problem-solving exercise where the student has to explain the development of the solution. This reduces the anxiety. And add: "It is important to stress that the problems should be simple and straightforward - the purpose of this assignment is to provide students with practice in constructing a "whole", not a "part", since beginning accounting students often have encapsulated or disconnected knowledge of the accounting process" (2004: 177).

The third exercise or one-minute response to an instructor's question is not related to the second nor after that. On the contrary, students sign up for a day to this activity. The topic can be anything seen that day and the teacher will give clues for the students to develop. The fourth exercise is based on a recent piece of news related to business. Students have to summarize the article. Some pieces of advice are also provided. The final presentation was evaluated by external physicians.

\section{Methodology}

This exercise represents the task done in one of the units of the subject. This is Strategies for the Learning of Modern Languages and in this subject all the different skills are reviewed. Three weeks are dedicated to this unit and in the first two different strategies are seen, not only related to the exposition itself but also to the preparation. Indeed, more importance is given to the first part than to the result itself, added to the collaborative work.

The exposition of a topic chosen by them has different steps. Firstly, they have the opportunity to choose the topic, comment to the teacher in order not to be repeated and not too wide (for instance, pop music is too 
open, anything would be treated very superficially). This is an advantage over other topics they could not be so interested in. Groups are formed as they like and they have to decide the topic and organize the tasks. This is done in class and in English. The teacher will check it. The sections, information, inclusion of videos or other extra materials will be discussed. Each of the members will have three minutes to explain their section and this can be added with some audio material.

But before that students received some notions on the tips to take into account when preparing and delivering a topic aloud. These tips have to do with the steps to be followed for gathering the information and how to organize the work in groups. As the visual presentation is also important some pieces of advice are given to them to have clear slides.

Secondly, they meet and reconvene in class to decide which topic they will talk about for being them varied. As said before, they must be as narrow and accurate as possible. They can also insert some audio material and this would represent extra time for the presentation as every single member must speak three minutes in their presentation. Transition between students and slides will also be considered.

Having decided the topic to talk about they will have to organize the material. For this an extra class will be offered to them in order to solve the questions to the teacher. They can bring their laptops and decide what part every student will explain. The teacher will offer at the end of the class a video taken from youtube in which two students deliver an oral presentation quite perfectly (see "Effective oral presentations"). This couple fulfills all the different elements for a quite perfect oral presentation.

Done this it is expected that students search for the information required at home and they will have to meet once or twice to decide what is useful or not and what is the order of the information, and so on. Students are expected to practice in groups the whole exposition. Slides will also be graded as consistency is expected.

The assessment of the activity must be clearly explained from the very beginning. In this way teachers state that collaboration between the members of the group is crucial as the final mark will have a high percentage of cohesion. So the assessment will be $60 \%$ personal delivery and $40 \%$ group cohesion.

When all the different groups have finished with the exposition they will be required to answer a survey on the preparation and delivery of the topic. This is anonymous and is answered online. The questions were offered in the mother tongue to avoid misunderstandings. The survey is attached as appendix 1 and translated into English.

\section{Results}

70 students out of 100 answered the survey so the sample is meaningful. They could do it at home or in class. I offered some minutes in order not to forget doing that. They are eleven questions and, as you can see in the appendix 1 , they are more related to the preparation rather than to the delivery itself. I consider that for the improvement of the oral skill is completely necessary to follow the patterns and different tips and acquire them as normal for any future delivery. They are language students so it will be very common to make more deliveries and if in the future they are English teachers class explanations aloud will be dealt with daily.

Results show next:

For the question 1 , the time dedicated to the preparation of the class, most of the students (44\%) consider that they dedicated more than four hours and, secondly, between two and four hours, around $27 \%$. For the question 2, the sources reviewed for the elaboration, more than one answer was allowed. Incredibly, quite all of them used the internet, not just google (97\%) but also youtube (51\%) was reviewed. The percentage for other sources is incredibly low. 


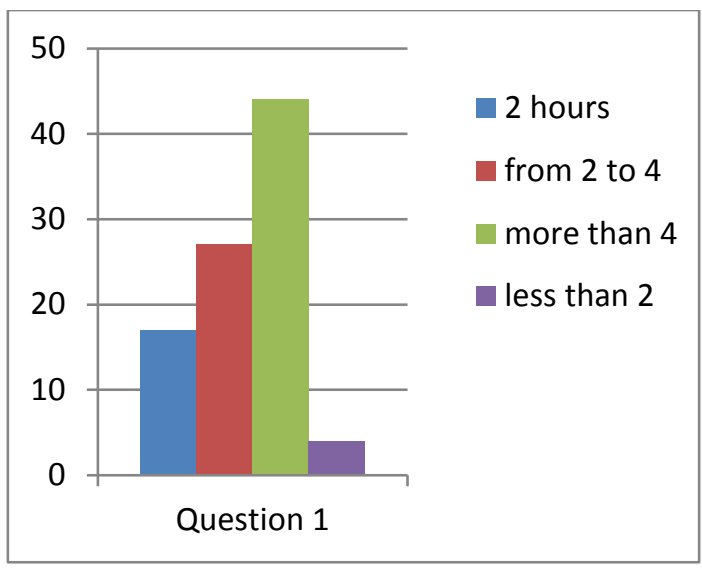

Figure 1: Results of question 1. Time dedicated to the preparation of every individual section.

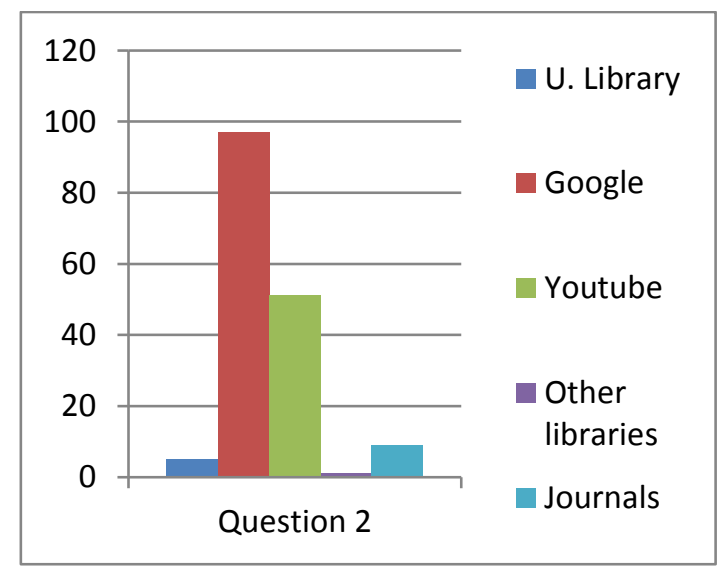

Figure 2: Results of question 2. Sources.

Question 3 refers to the times they gathered to prepare the content of the exposition. Answers between once and three times are similar. Twice (35\%), three times (28\%), and once (24\%). Question 4 refers to the times they reunited to practice the exposition and most of them answer that only once (54\%); very few people more than once and $11 \%$ never.

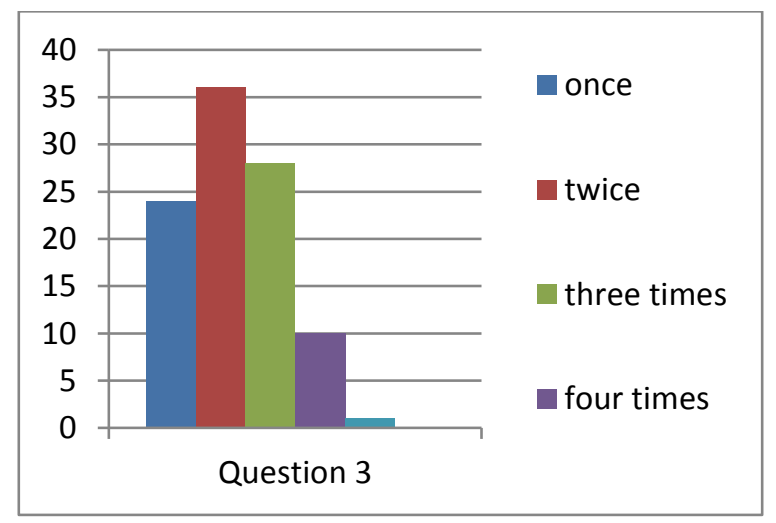

Question 3. Number of times you meet the group to elaborate the information. 


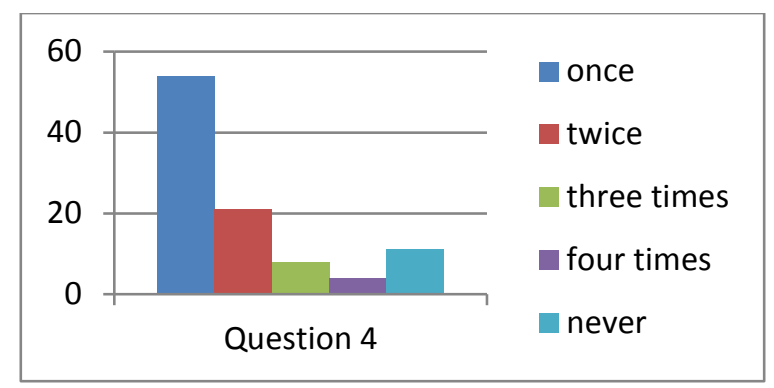

Question 4. Number of times you practiced with the group.

$94 \%$ of the students reviewed the information seen in class and $92 \%$ considered it useful. Added to this, $81 \%$ consider they have improved in the oral skill but not all of them fell satisfied with the result (61\%). Quite all of them consider that could have been done better (94\%). Next question deals with what to do to make it better. Most of them consider that they should practice more often (58\%); to know exactly what they want to talk about and record the intervention has the same percentage (30\%).

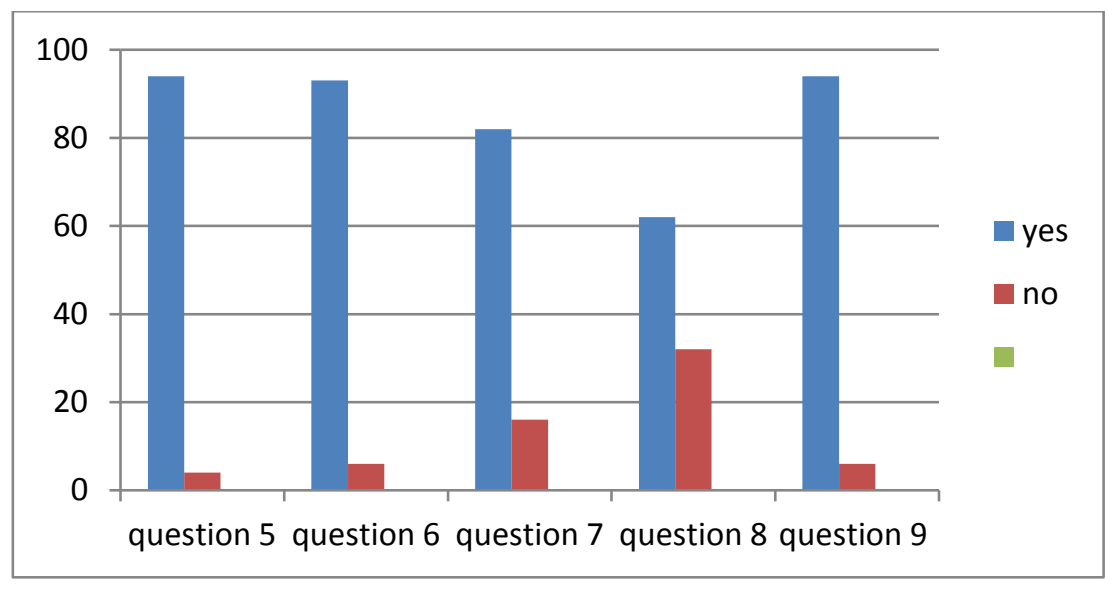

Results of questions 5 to 9: 5 , revision of the information received; 6 , usefulness of the information received; 7 , improvement; 8 , satisfaction; 9 , whether it could be done better.

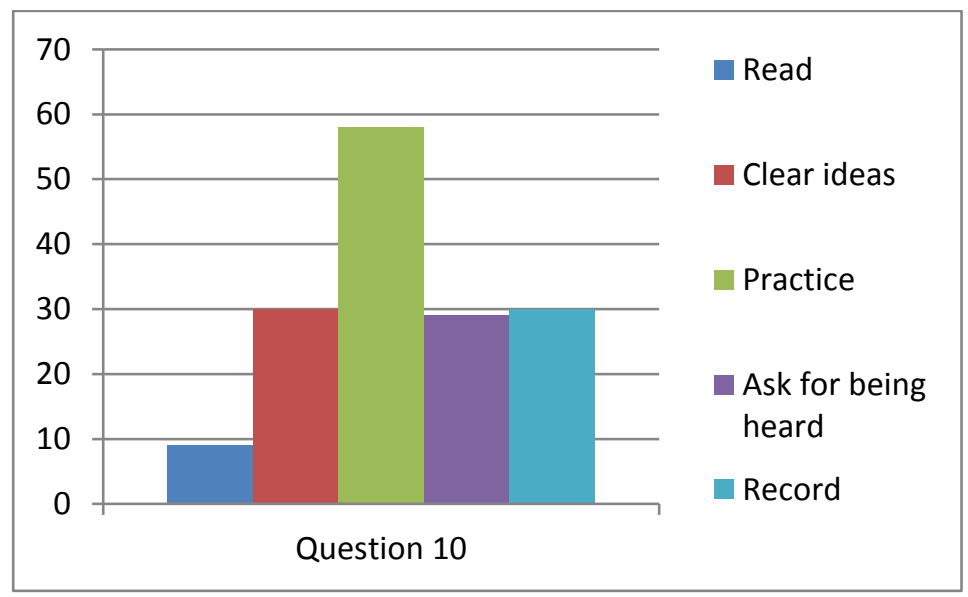

Results of question 10: What to do to improve the oral expositions. 
And when they were asked what they missed in class results were: More theoretical information about how to talk in public (47\%); more information about nonverbal language (25\%); more practice in class (15\%), more information about visual support (18\%), and nothing (21\%).

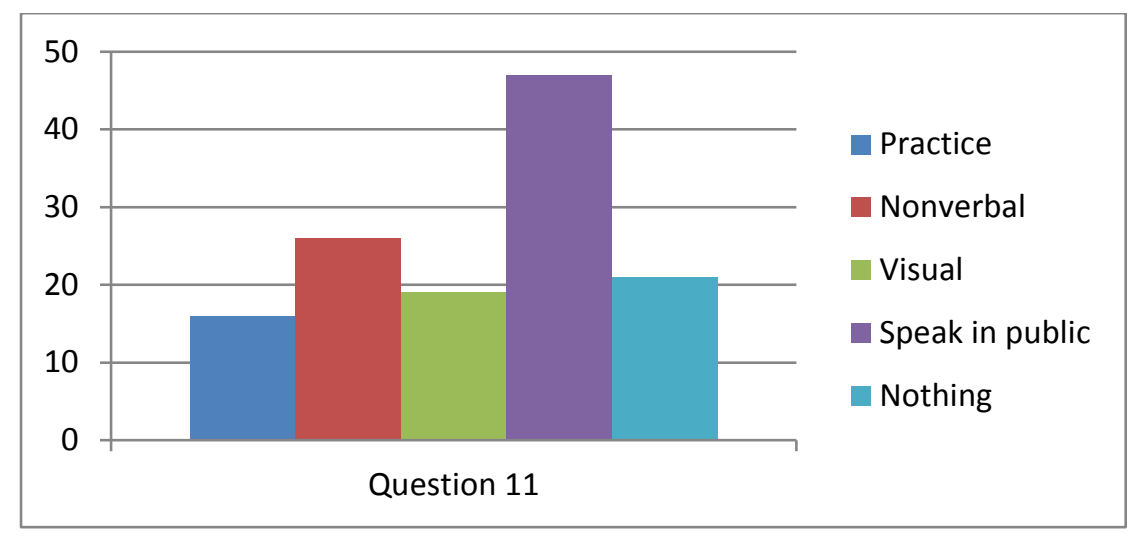

Results of question 12: What you missed in the theoretical information of the teacher

\section{Discussion}

A disadvantage of the exercise with freshmen students that do not know each other is that they have to work together without any previous reference of them, their way of studying, English level and so on. In this way the interaction will need extra time to get the work organized. An advantage could be drawn in that this is a first step for them to break the ice and start getting in touch in an academic environment.

One of the reflections that arise with this survey is the need to make the students use other sources to find information as the library. Maybe journals have a high level for them as they are checking topics in an average level but books and magazines could be reviewed. Another element that has attracted my attention is the scarce number of times they have reunited to prepare the exposition. I consider this section important but if they divide the sections into the number of students they do not need to know much about what the others will say. One solution for this could be to be the teacher the one who tells them the delivery day what section they have to talk about. In this way all the students must know about all the information.

\section{Conclusions}

Confidence is revealed as a crucial element when practicing oral production. Indeed, the need of a good atmosphere in the group is an indispensable condition for the disposition of the students to speak aloud.

One of the improvements that could be done for next years is to offer them the topics they have to talk about or, if they choose them, to make them review bibliography from the library. They will have to justify this bibliography. The use of the library is a source that they cannot take for granted. The information, resources and possibilities it has represent a tool that they must know from the very beginning of the degree.

The need to implement new technologies and all the gadgets used by students to the oral classes seem compulsory. Added to this, the need to do more than one presentation looks useful for the students as the results are always better. Following Tsai and adapting his courseware design, one option could be the recording of one-minute presentation on the mobile phone or a pen drive in order to be able to offer a feedback.

Another conclusion is related to the items to be evaluated. It is necessary to open and widen the scope, as Tsai proposes. Nonverbal language is quite as important as the communication itself and students must be aware 
of this. For this the need to do two exercises: one as preparatory of the second and in which they have to record themselves and analyze are these elements look beneficial to them.

Offer a guided presentation in which the students have to follow some outline.

\section{Works Cited}

Cohen, A. D. (1998). Strategies in learning and using a second language. London: Longman.

Cohen, A. D., \& Dörnyei, Z. (2002). "Focus on the language learner: Motivation, styles, and strategies." In N. Schmitt (Ed.), An introduction to applied linguistics (pp. 170-190). London: Arnold.

"Effective Presentations Introduction (APA / Harvard)" in Youtube

https://www.youtube.com/watch?v=ewVCnfMGnFY (accessed 05.04.2017)

Gallagher-Brett, Angela. "What do Learners' Beliefs about Speaking Reveal about their Awareness of Learning Strategies?" The Language Learning Journal 35.1 (2007): 37-49. Web.

Myers, S. "Using written text to teach oral skills: an ITA training class using field-specific materials" in English for Specific Purposes 14: 3, 231-245. 1995.

Yu, Xiaoxue. "Oral English Learning Strategies." Theory and Practice in Language Studies 3.10 (2013): 1902. Web.

\section{Appendix 1}

Question 1. How long did you dedicate for the preparation of your part:
a. Two hours
b. $\quad$ From two to four hours
c. Less than two hours
d. More than four hours

Question 2. Indicate in what sources you found the information
a. In the library of the faculty
b. On the Internet (google,...)
c. On the Internet (youtube)
d. In other libraries
e. In journals

Question 3. How many times did you meet the group to elaborate the exposition?
a. Once
b. Twice 
c. Three times

d. Four times

e. $\quad$ More than four times

f. Never

Question 4. How many times did you meet the group to practice the exposition?
a. Once
b. Twice
c. Three times
d. Four times
e. Never

Question 5. Did you review the information seen in class to deliver your exposition?
a. Yes
b. No

Question 6. Do you feel it useful?
a. Yes
b. No

Question 7. After the delivery, do you consider you have improved this skill?
a. Yes
b. No

Question 8. Are you satisfied with the result?
a. Yes
b. No

Question 9. Do you consider you could have done it better?
a. Yes
b. No

Question 10. What can you do to improve the oral expositions in English?
a. Read more about the topic
b. Know what exactly I want to talk about 
c. Practice more times

d. Asking for a friend/ relative to listen to me

e. $\quad$ Record my section

Question 11. What did you miss in the theoretical lesson seen in class?
a. $\quad$ More practice in class
b. More information about nonverbal language
c. More information about visual support
d. More information about how to talk in public
e. Nothing 